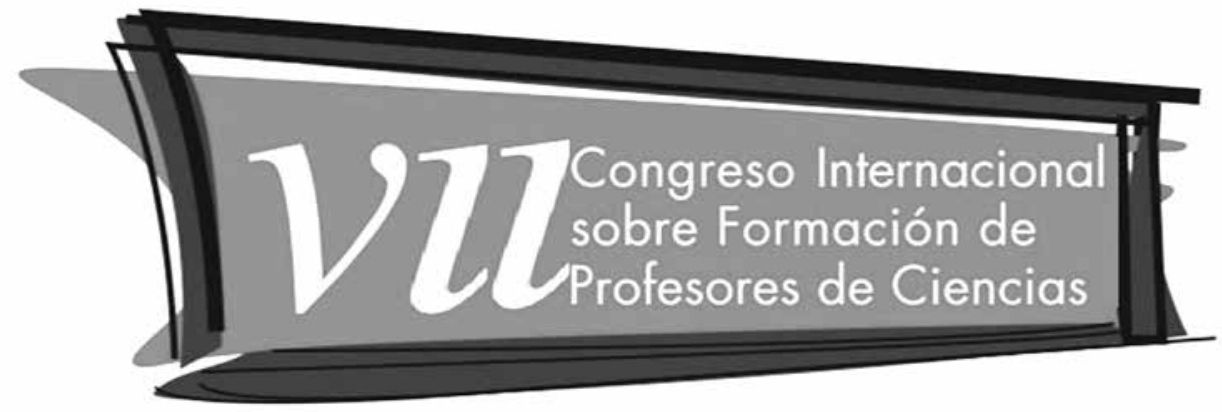

\title{
Desafíos de la Educación en Ciencias para la transformación de las prácticas docentes
}

\section{Octubre 12, 13 y 14 de 2016 Bogotá, Colombia}

\section{Primera comunicación}

\section{Introducción}

Desde el año 2003 se viene realizando de manera ininterrumpida el Congreso Internacional de Formación de Profesores de ciencias, el cual ha constituido un espacio de divulgación académica de importante reconocimiento iberoamericano, a propósito de los problemas asociados a la formación de profesores y a la Educación en Ciencias.

La participación de profesores e investigadores de los distintos países de América Latina, Portugal y España dan cuenta de la riqueza académica del evento y de su posicionamiento internacional.

Atendiendo a los compromisos adquiridos con la comunidad académica, la Universidad Pedagógica Nacional y la Universidad Distrital invitan a participar en la VII versión de este congreso, el cual propone como tema de discusión los desafíos de la Educación en Ciencias para la transformación de las prácticas docentes.

En la próxima comunicación informaremos sobre el total de instituciones organizadores y patrocinadoras del evento, así como lo concerniente a inscripción y pago.

\section{Temas}

El VII Congreso sobre Formación de Profesores de Ciencias propone las siguientes líneas de trabajo conforme la temática general del evento:

1. Relaciones entre investigación y enseñanza.

2. Relaciones escuela y entorno escolar.

3. Relaciones entre políticas y normatividad en la formación del profesorado de ciencias. 
4. Relaciones con otras áreas curriculares de la organización escolar.

5. Relaciones entre modelización, argumentación, contextualización, e historia, epistemología y sociología de la ciencia.

6. Relaciones entre los enfoques CTSA y Educación Ambiental.

7. Relaciones entre escuela - universidad.

8. Relaciones entre TIC y nuevos escenarios didácticos.

9. Relaciones entre Educación en Ciencias, diversidad, inclusión, multiculturalismo, interculturalidad y género.

\section{Modalidades de participación}

Se recibirán comunicaciones para ser presentadas como ponencias o póster (modalidad que define el Comité Científico), en relación con los temas definidos y dentro de una de las dos categorías (que definen los autores):

- Categoría 1: Reflexiones y experiencias desde la innovación en el aula.

- Categoría 2: Trabajos de investigación (en proceso o concluidos).

\section{Requisitos de las comunicaciones}

Las comunicaciones deben tener en cuenta la siguiente estructura:

Título Centrado, negrita y a 14 pt

Autores: Primer autor y demás autores en este orden: apellido, nombre, -justificado a la izquierda-. La institución y el correo electrónico van como Nota al pie a 10 pt.

Resumen: Con una extensión máxima de 750 caracteres sin espacios.

Palabras clave: Debe contener entre 3 y 5.

Categoría: Definir si es la 1 ○ 2.

Texto: Todo el texto tendrá una extensión entre 7.500 y 11.500 caracteres sin espacios, incluyendo gráficos, tablas, figuras, referencias bibliográficas, etc. Este texto debe tener la siguiente Estructura y cumplir con las Normas definidas:

Estructura del texto: Para los presentados como Reflexiones debe contener Introducción, Desarrollo y Referencias bibliográficas (según normas APA 6ta Edición 2010). Los presentados como Investigaciones, tendrán Objetivos, Marco teórico, Metodología, Resultados, Conclusiones y Referencias bibliográficas (según normas APA 6ta Edición 2010).

Normas del escrito: El tipo de letra es Century Gothic, 11 pt, Texto justificado; Interlineado 1,15. Tamaño carta, con márgenes superior e inferior de 2,5 cm y márgenes izquierda y derecha de $3 \mathrm{~cm}$. Solo debe haber la nota al pie relacionada con la institución y el correo electrónico del autor o autores. 
Los gráficos, tablas, figuras, deben estar numeradas y nombradas en la parte superior de éstos.

Las comunicaciones deberán enviarse a través correo electrónico a congreso.formacion.profesores@gmail.com

Fechas importantes

\begin{tabular}{l|l}
\hline \multicolumn{1}{c|}{ ACTIVIDADES } & \multicolumn{1}{c}{ FECHAS } \\
\hline Envío de Comunicaciones (Primer Autor) & $\begin{array}{l}\text { 30 de NOVIEMBRE DE 2015 al 18 de ABRIL } \\
\text { DE 2016 }\end{array}$ \\
\hline $\begin{array}{l}\text { Evaluación de Comunicaciones (Comité } \\
\text { Científico) }\end{array}$ & Hasta el 30 de MAYO \\
\hline $\begin{array}{l}\text { Notificación de la evaluación (Secretaría } \\
\text { Técnica) }\end{array}$ & Hasta el 16 de JUNIO \\
\hline $\begin{array}{l}\text { Envío de Comunicaciones ajustadas - texto } \\
\text { completo (Primer Autor) }\end{array}$ & Hasta el 30 de JUNIO \\
\hline $\begin{array}{l}\text { Envío del Resumen de 200 caracteres para la } \\
\text { agenda (Primer Autor) }\end{array}$ & 02 al 06 de JUNIO \\
\hline \begin{tabular}{l} 
Realización del CONGRESO \\
\hline
\end{tabular} & OCTUBRE 12, 13 y 14 de 2016 \\
\hline
\end{tabular}

